\title{
Do we need research on reporting on diabetes research?
}

\author{
Massimo Porta ${ }^{1} \cdot$ Massimo Federici $^{2} \cdot$ Antonio Secchi $^{3}$
}

Published online: 9 January 2016

(c) Springer-Verlag Italia 2015

Two years ago we celebrated Acta Diabetologica's fiftieth anniversary [1] and then proceeded to bring in a number of changes to help it meet the challenges that await diabetes research, and the reporting of diabetes research, in the next 50 years. The Advisory Board was enlarged to members from all over the world, and we take this opportunity to thank them for accepting an additional burden to their already busy schedules. Secondly, we strived to maintain the shortest possible processing times for submitted manuscripts, and the latest statistics testify that we are managing to do so.

Third, we worked to manage a consistent backlog of online first published articles. This was meant to meet authors' reasonable expectations to have their own articles included in a published issue. This policy might have contributed to the fluctuation of the impact factor although we are fully aware that selecting high-quality papers will be the only valuable strategy to have it rise again. Indeed, as Editors, we were happy to see the quality of submitted manuscripts steadily improving over the past two years and feel confident that bibliometric indexes will eventually

Massimo Porta

massimo.porta@unito.it

Massimo Federici

federicm@uniroma2.it

Antonio Secchi

antonio.secchi@hsr.it

1 Department of Medical Sciences, University of Turin, Corso AM Dogliotti 14, Turin, Italy

2 Department of Systems Medicine, University of Rome Tor Vergata, Via Montpellier 1, 00133 Rome, Italy

3 Vita-Salute San Raffaele University, Via Olgettina 60, 20132 Milan, Italy reward our efforts to make Acta Diabetologica more and more of an outstanding journal.

With a historical perspective on the past 50 years, we open this first issue of 2016 with a report on the 100 most cited papers of all times in the field of diabetes research [2]. Though not revealing major surprises, the report confirms that randomized controlled clinical trials, headed by the DCCT and UKPDS, and position statements/guidelines, remain most popular among research workers. However, interestingly and perhaps refreshingly, some "classical" pathophysiology milestones also sit high in the premier league. Pathophysiology lays the foundations, but final answers on diagnosis and treatment can only come from intervention studies, with all the caveats that still surround the translation of trials to the real world. Also the country of origin of top papers, headed by the USA, and the journals in which they were published, sadly Acta Diabetologica is not among them, reserve few surprises, confirming the quality of knowledge produced in areas with a strong tradition in diabetes research. Indeed, even if citations are not necessarily synonymous with quality, we can assume that the equivalence holds true at least in the Heaven of the top 100 .

For lesser reports, or top 100 to be, selection for publication remains based upon time-honored peer review, a process fraught with shortcomings except that, as someone said about democracy, any alternative is worse. A novel set of trials and tribulations has emerged recently when a number of papers were retracted because authors were found to have suggested themselves (under false names and addresses) and/or complacent friends as reviewers. Subsequent investigations revealed even more sophisticated rings of fraudulent agencies that, for a fee, provide authors with both fabricated articles and friendly reviewers [3]. Sadly, the drive to publish or perish has turned research from the 
liberal art that it used to be into a booming business for the publishing industry and an avenue to brilliant careers for unscrupulous individuals. Worryingly, this happens, and is definitely not helping, while militant anti-science movements are gaining momentum in the wide world outside, as "lay" people doubt the very methods and ultimate goals of research. Thus, perish the pursuit of knowledge and the "sanctity" of science?

Not necessarily but, while waiting for alternative ways to incentivize research, a number of steps can be taken to curb misbehavior on reporting. For one, Acta Diabetologica is member of the international Committee on Publication Ethics (COPE) [4], providing guidance to prevent authors' misconduct, and this is now formally acknowledged in the journal's website. More to the point in question, although we have traditionally asked authors to suggest reviewers at the time of submission, these have been used sparingly, only after checking their credentials, and altogether avoided if in doubt. In any event, as of this year, indicating reviewers will no longer be an obligatory step in the submission process but will rather remain an option that, if properly motivated, will allow authors to suggest which experts they believe will provide learned but independent opinions.
Having said all that, honest, proper reviewers are the salt of a journal, and we take this opportunity to thank all those who evaluated submissions to Acta Diabetologica over the past year. As handling editors, we take every possible step to avoid imposing unnecessary burdens on them, as we realize that their precious time is the very gift they make to us. Although probably a meager reward, and debate on more tangible forms of acknowledgement are being discussed in the editing world [5], we gratefully list all those who helped us as reviewers during 2015.

\section{References}

1. Porta M (2014) Acta diabetologica is 50 and well. Long live acta! Acta Diabetol 51:1-5

2. Zhao X, Guo L, Lin Y, Wang H, Gu C, Zhao L, Tong X (2015) The top 100 most cited scientific reports focused on diabetes research. Acta Diabetol. doi:10.1007/s00592-015-0813-1

3. Haug CJ (2015) Peer-review fraud-hacking the scientific publication process. N Engl J Med 373:2393-2395

4. http://publicationethics.org/

5. Fuster V (2015) A praise for reviewers: how do we reward them? JACC 65:212-213 